\title{
Research Paper: Investigating the Relationship Between Lower Limb Flexibility With Motor Function and Risk of Falling in Visually Impaired Individuals
}

\author{
Kamal Mohammad Khani' ${ }^{1}$, Mohammad Karimizadeh Ardakani ${ }^{1}$ (D), Mohammad Hani Mansori ${ }^{*}$ (iD
}

1. Department of Health and Sport Medicine, Faculty of Physical Education and Sport Sciences, University of Tehran, Tehran, Iran.

\begin{tabular}{|c|c|}
\hline $\begin{array}{l}\text { Use your device to scan } \\
\text { and read the article online }\end{array}$ & ditation Mohammad Khani K, Karimizadeh Ardakani M, Hani Mansori M. Investigating the relationship Between Low- \\
\hline 口ifing & $\begin{array}{l}\text { er Limb Flexibility With Motor Function and Risk of Falling in Visually Impaired Individuals. Physical Treatments. 2021; } \\
\text { 11(2):93-102. http://dx.doi.org/10.32598/ptj.11.2.429.2 }\end{array}$ \\
\hline arys & dol: http://dx.doi.org/10.32598/ptj.11.2.429.2 \\
\hline
\end{tabular}

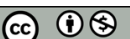

Article info

Received: 14 Jun 2020

Accepted: 10 Oct 2020

Available Online: 01 Apr 2021

Keywords:

Blindness, Flexibility,

Balance, Falling, Function

\section{A B S T RA C T}

Objective: The present study aimed to investigate the flexibility of the ankle and knee joints and to determine its relationship with balance, motor function, and risk of falling in visually impaired individuals.

Methods: The sample consisted of 32 blind males, 20-30 years old. They were selected by the purposeful sampling method. We used modified stork tests, tendon gait, and Berg balance scale to evaluate their balance. The Tinetti test was used to evaluate motor performance and the Timed Up and Go (TUG) test to assess the risk of falling. The SLR test and Lunge test were used to assess the range of motion of the knee and ankle joint, respectively. This study was conducted in the men's dormitories of Tehran University in the fall of 2019. The obtained data were normalized using the Shapiro-Wilk test and Pearson correlation coefficient at the significant level of 0.05 to investigate the relationship between the variables.

Results: The results of the Pearson correlation test showed a significant relationship between balance $(\mathrm{P}=0.001)$, motor function $(\mathrm{P}=0.002)$, and TUG fall risk test $(\mathrm{P}=0.010)$ (ankle motor restriction). On the other hand, there was a significant relationship between balance $(\mathrm{P}=0.002)$, motor function $(\mathrm{P}=0.001)$, and TUG fall risk test $(\mathrm{P}=0.003)$ with hamstring flexibility test (knee motor restriction).

Conclusion: Given the significant relationship between the range of motion of the lower limbs with balance and motor function, the use of stretching exercises can be an influential factor in increasing the range of motion of the ankle and knee in blind people, which improves balance, motor function, and reduced risk of falling in blindness.

\footnotetext{
* Corresponding Author:

Mohammad Hani Mansori, MSC.

Address: Department of Health and Sports Medicine, Faculty of Physical Education and Sport Sciences, University of Tehran, Tehran, Iran

Phone: +98 (935) 5301573

E-mail: haninio74@gmail.com
} 


\section{Highlights}

- People who are blind had limited mobility in each dominant and non-dominant limb of the ankle and knee joints.

- There is a significant relationship between ankle and knee flexibility with balance, motor function and risk of falling in visually impaired Individuals.

- The use of stretching exercises can be an effective factor in increasing the range of motion of the lower limb joints of visually impaired Individuals.

\section{Plain Language Summary}

Blindness knows no borders and can affect people regardless of age, gender, nationality, religion, race and social and economic class. Visual impairment both psychologically and physically affects a person's daily and natural activities and causes problems in orientation, accurate and correct movement in the direction of joint movement, social dependence and decreased self-confidence. As a result of these people, due to the fear of injury during movement and daily activities, the amount of physical activity decreases and the person may become sedentary. Decreased exercise and inactivity is one of the things that blind people deal with, which can lead to dysfunction of various joints in the body. Decreased range of motion can occur due to lack of proper exercise and low mobility. As a result, joint activity, muscle length, and range of motion of the joints are also affected, and in the end, the entire musculoskeletal, nervous, and joint systems of the body are disrupted, which also causes dislocation and damage in these organs.

\section{Introduction}

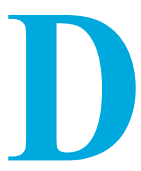

uring the past few decades, health has been recognized as a social goal worldwide. In other words, the basic human needs should be satisfied, and their quality of life should be improved. There are a large and growing number of people with disabilities in today's world [1]. Blindness and low vision are the most common disabilities. According to the World Health Organization (WHO) estimates, 285 million people are visually impaired worldwide, of whom 39 million are blind, and 246 million have low vision. Approximately $90 \%$ of the visually impaired people live in developing countries, and $28 \%$ of them are between 15 and 49 years old [2]. Besides changes in balance control, vision loss can increase dependence, limit daily life activities, reduce self-confidence, and increase the risk of falling $[3,4]$. This system also gains information regarding the direction of the head movements. The sight has been shown to play an essential role in maintaining postural stability [5]. Decreased balance is one of the most common complications of vision impairments [6].

On the other hand, the challenges faced by blind people include reducing personal independence and physical activity levels, which may limit the movement of one or more joints. Reduced Range of Motion (ROM) due to increased muscle and connective tissue stiffness can in- crease the incidence of falls [7]. The muscle-tendon stiffness and toughness of the tissues around the joint have been shown to result in reduced ROM, which is positively associated with decreased balance and increased fall risk [8]. Studies have shown that reduced knee and ankle ROM has been identified as one of the leading causes of falls due to its effect on the dynamics of the lower limbs during walking [9]. The strength of flexor muscles of the ankle and the inversion-eversion ankle ROM affect balance and motor function [10].

Basnett et al. investigated the effect of ankle dorsiflexion ROM on the dynamic balance in individuals with Chronic Ankle Instability (CAI) [11]. Their results showed a significant correlation between the dorsiflexion ROM and the anterior reach direction and posterolateral reach direction [11]. The results of a study conducted by Seong-Gil Kim et al. demonstrated a significant relationship between ankle plantarflexion and static balance [12]. It has been shown that the full hip joint ROM and the plantar flexion-extension at the ankle joint in the elderly, who have a history of falls or those with no history of falls, are lower than those in young people. Because the joint ROM is affected by antagonist muscle stiffness, the weakness and shortness of antagonist muscle and the lack of proper stretching exercise during daily activities may change joint movement and limit the mobility of people who do not exercise regularly or those with a sedentary lifestyle [7]. 
The hamstring muscle has been shown to play a significant role in the knee ROM, and hamstring stretching exercise can significantly affect the knee ROM [13]. Studies show a positive association between the knee ROM and balance and flexibility. Also, they indicate that muscle stiffness and limited knee mobility can result in reduced balance [14]. Several studies have shown that lack of muscle flexibility (ROM) can negatively affect balance and motor function. Hoch et al. investigated the effect of ankle dorsiflexion ROM on dynamic balance in young people. Their results showed that the ankle dorsiflexion ROM limitation significantly influenced dynamic balance [15]. Jeong-Woo Lee et al. examined the effect of ankle ROM on the balance performance of older adults, and their results demonstrated that the defect in the ankle joint ROM significantly influenced balance. The study was conducted on elderly people with poor mobility of their lower limbs, decreased ROM in their knee, and reduced balance. The study also indicated that increasing the ankle ROM could improve balance in these people [16]. To the best of our knowledge, no studies have been conducted on the association between lower extremity ROM and some physical and motor factors for blind people. Therefore, this study aimed to investigate whether there is a limitation in knee and ankle range of motion in blind people or not. And if so, is there a significant association between the balance, motor function, and falling risk?

\section{Methods}

This research was a descriptive correlational study. The study population consisted of all blind male university students in Tehran City, Iran. Of whom, 32 students with congenital blindness studying at the University of Tehran were selected using a purposeful sampling method. The samples' characteristics were the type of blindness (congenital blindness) and its severity (absolute blindness and low vision). The inclusion criteria were as follows: absolute blindness with no other disabilities; males in the age range of 20 to 30 years; not a professional athlete or a member of a sports team; no fractures of the lower limb, history of lower limb surgery, or history of the knee injury; voluntary participation in study and comprehension of the research guidelines.

The exclusion criteria consisted of any pain during exercise; failure to complete tests, using medications that can affect the samples' balance; lack of participation and withdrawing from the study; pain, disability, or dizziness while performing the examination tests. After selecting the subjects based on the study inclusion and exclusion criteria and explaining the research purpose, they were asked to consent to participate in the study. Afterward, the examiner completed the questionnaire for all subjects and recorded their information such as name, age, height, weight, athletic background, and contact number.

\section{Measurement tools}

The ankle joint Lunge test to assess ankle joint ROM

The sample stands against the wall about $10 \mathrm{~cm}$ between feet and wall. Then, he moves one foot back a foot's distance behind the other one and bends the front knee until it touches the wall (keeping the heel on the ground). If the knee cannot touch the wall without the heel coming off the ground, the subject should move his foot closer to the wall and then repeat the procedure. If the knee can touch the wall without the heel coming off the ground, the sample should move foot further away from the wall and then repeat the procedure. Until the sample can just touch knee to wall and heel stays on the ground; the distance between the wall and big toe is measured [17] (Figure 1).

\section{Straight Leg Raise (SLR) test to assess the knee joint ROM}

The 90-90 Straight Leg Raise (SLR) test is used to measure hamstring flexibility. The sample lies supine with the hips and knees flexed to $90^{\circ}$ and grasps behind both of his thighs to stabilize the hip joints, then actively extends each knee in turn. Keeping the knees in about $70^{\circ}$ of flexion indicated that the person does not have short hamstrings, and knee flexion less than $70^{\circ}$ indicated that the person has short hamstrings [18] (Figure 2).

\section{Modified Stork stand balance test}

The present-test was performed as follows: the participant stands with one foot on the flat surface and raises his free leg up to the ankle of the support leg; both hands were hanged free beside the body. Once the participant laid his free foot on the ground, the time stopped - the maximum time the participant stand on his leg was considered as his record. The test was performed twice on both legs, and the best time was registered as the record $[19,20]$ (Figure 3).

\section{Tandem walking test}

The Tandem walking test was used to measure the dynamic balance. By this test, the participant's capability in walking on a straight path in a way that toes of the back foot touch the heel of the front foot is evaluated. The test 


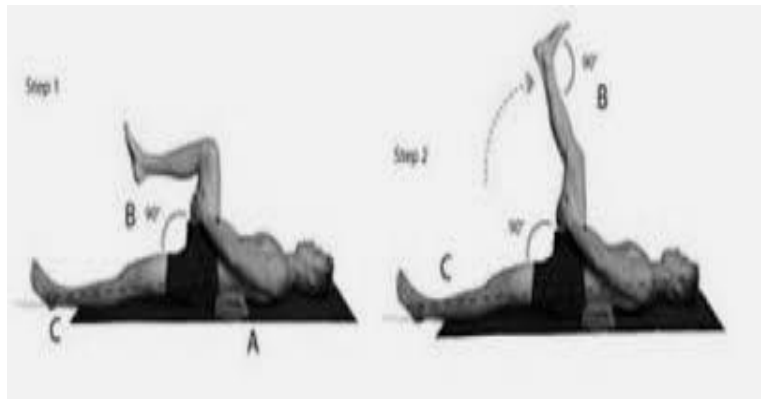

Figure 1. The lunge test

PHYSICAL TREA $\mid$ MENTS

was performed as follows: the participant walked on a certain path with a length of 15 steps, and the maximum score was 15 . If the participant was deviated from the path before completing 15 steps, the test was stopped, and the number of steps was recorded (Figure 4). The test was implemented twice, and the best score was recorded as the participant's record $[19,20]$. The reliability of this test was calculated as $0.91 \%$ [19]. Figure 5 depicts the mean scores obtained by samples.

\section{Falling risk or TUG}

This test was designed by Matthias in 1986 and had a scoring scale of 1 to 5. The Timed Up and Go (TUG) test consists of sitting on a chair, standing, and walking up to $3 \mathrm{~m}$, coming back, and sitting on a chair again. The criterion for this test is the time that a person takes to perform the motion maneuver from the moment of getting up from a chair to sitting down again, measured by a chronometer. The time of this test for young people is 5-7 seconds. The validity and reliability [21] of this test were reported to be very high [20,22]. At the end of the $3-\mathrm{m}$ path, a stick is used to the floor for blind people, and they notice a 3-m distance when reaching that point.

\section{Tinetti test}

This test was developed by Tinetti in 1986 and consisted of two parts. The first part involves examining sitting, getting up, and standing, and the second part involves

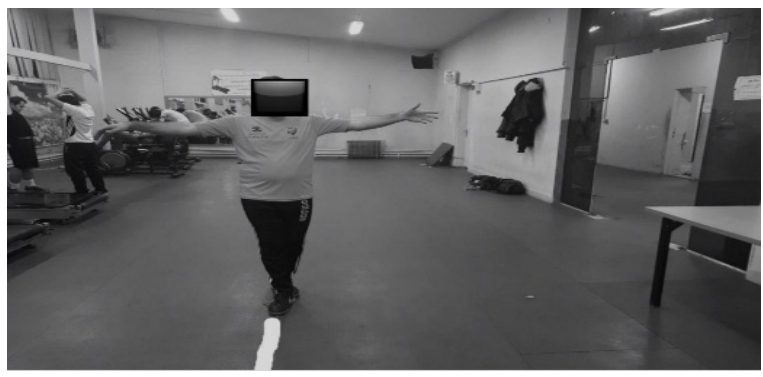

PHYSICAL TREA $\$ MENTS

Figure 3. Modified Stork stand balance test

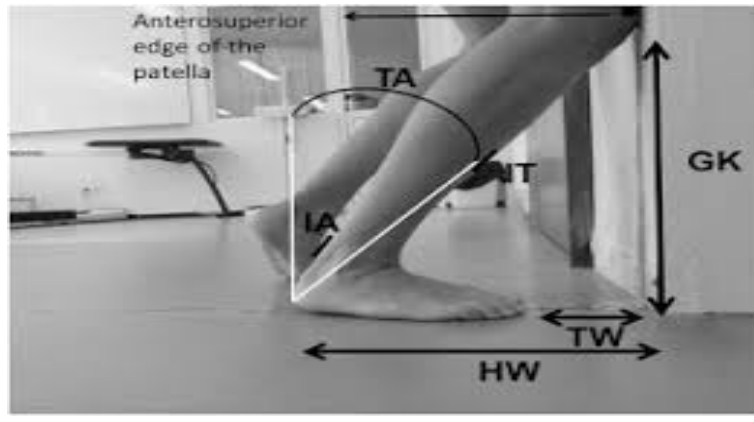

Figure 2. Straight leg raise

PHYSICAL TREA $\$ MENTS

examining gait. The first part consists of 9 motion maneuvers, and each section is scored from 0 to a maximum of 2 points. The second part involves the examination of 7 components of gait. The time required for the test is 10 to 15 minutes. The best score is 16 for the balance and 12 for gait, and in total, the best score is 28 . A score below 19 indicates a high risk of falling [20].

\section{Berg balance scale}

This scale consists of 14 items that objectively evaluate functional capabilities of posture and dynamic balance and involves daily activities such as sitting, standing, and moving, to each of which a score of 0 to 4 is assigned based on the type of implementation. The score ranges are 41-56 (lowest risk of falling), 21-40 (average risk of falling), and 0-20 (high risk of falling). The sum of these scores for 14 items for each individual predicts the risk of falling and loss of postural control [20,23].

The data obtained from the evaluation of the tests to determine mobility limitation in blind people and its association with the study variables were recorded and entered into SPSS v. 24. In the present study, the obtained data were interpreted using descriptive and inferential statistics. The data distribution for normality was performed using the Shapiro-Wilk test. The ankle joint Lunge test (to assess ankle joint ROM), the SLR test (to

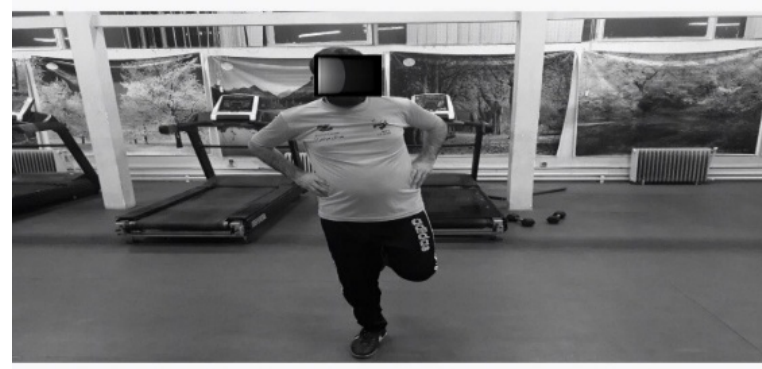

Figure 4. Tandem walking test 
Table 1. Demographic characteristics of the subjects in two groups

\begin{tabular}{ccccc}
\hline Variables & No. & Means \pm SD & Minimum & 20 \\
\hline Age $(\mathrm{y})$ & 32 & $32.39 \pm 23.9$ & 63 & 29 \\
\hline Weight $(\mathrm{kg})$ & 32 & $75.62 \pm 5.25$ & 159 \\
Height $(\mathrm{cm})$ & 32 & $169.34 \pm 6.32$ & 184 \\
BMl $\left(\mathrm{kg} / \mathrm{m}^{2}\right)$ & 32 & $26.51 \pm 3.09$ & 33.59 \\
\hline
\end{tabular}

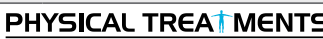

assess the knee joint ROM), and the Pearson correlation coefficient $(\mathrm{P}<0.05)$ were used to investigate the association between static and dynamic balance, motor function, and falling risk.

\section{Results}

Table 1 presents the descriptive characteristics of the subjects, including height, weight, age, and Body Mass Index (BMI). Table 2 presents the mean scores obtained from ankle and knee mobility limitation tests. As seen in Table 2, blind people had mobility limitations in dominant and non-dominant limbs in the ankle and knee.

The Pearson correlation coefficient results indicated significant correlations between the scores obtained from the Lunge test (to assess ankle joint ROM) with static balance (in dominant limb $(\mathrm{P}=0.001)$ and non-dominant limb $[\mathrm{P}=0.007])$, dynamic balance in dominant $\operatorname{limb}(\mathrm{P}=0.001)$, and non-dominant limb $[\mathrm{P}=0.022])$, the Berg balance scale in dominant $\operatorname{limb}(\mathrm{P}=0.001)$ and non-dominant $)$ $\operatorname{limb}(\mathrm{P}=0.035)$, Tinetti test in dominant $\operatorname{limb}(\mathrm{P}=0.002)$ and non-dominant $\operatorname{limb}(\mathrm{P}=0.025$ and timed up and go test in dominant limb $(\mathrm{P}=0.010)$ and non-dominant limb $(\mathrm{P}=0.003)$ for blind people $(\mathrm{P}<0.05)$ (Tables 3 and 4$)$.

The Pearson correlation coefficient results showed significant correlations between the scores obtained from the SLR test (to assess the knee joint ROM) with static balance in dominant $\operatorname{limb}(\mathrm{P}=0.002)$ and non-dominant limb $(\mathrm{P}=0.004)$, dynamic balance in dominant limb $(\mathrm{P}=0.001)$, and non-dominant $\operatorname{limb}(\mathrm{P}=0.001)$, the Berg balance scale in dominant $\operatorname{limb}(\mathrm{P}=0.001)$ and non-dominant limb $(\mathrm{P}=0.004)$, the Tinetti test in dominant limb
$(\mathrm{P}=0.001)$ and non-dominant limb $(\mathrm{P}=0.002)$, and TUG in dominant $\operatorname{limb}(\mathrm{P}=0.003)$ and non-dominant limb $(\mathrm{P}=0.001)$ for the blind people (Tables 5 and 6 ).

\section{Discussion}

According to the SLR test, keeping the knees in about $70^{\circ}$ flexion indicates that the person did not have short hamstrings, and less than $70^{\circ}$ indicates having a short hamstrings. The present study results showed that blind people had mobility limitation in dominant $(64 \pm 5.86$ degrees) and non-dominant (60 \pm 5.32 degrees) limbs at the knee and the knee joint. According to the ankle joint Lunge test, bending the knees less than $15 \mathrm{~cm}$ indicates that the person has mobility limitation in the ankle. Our results demonstrated that blind people had mobility limitation in dominant $(11.06 \pm 1.34 \mathrm{~cm})$ and non-dominant $(10.33 \pm 0.99 \mathrm{~cm})$ limbs at the knee and the knee joint. Accordingly, the limitations of blind people are very much like those of other people.

But in many cases, blindness imposes limitations on children for the games and activities that can slow down their physical growth. Houwen et al. found that children with visual impairment presented with poorer and weaker motor skills compared to children with normal visual acuity, and people with blindness have a more sedentary lifestyle and are at higher risk for mobility limitations and motor skills difficulties [24]. Poor motor skills lead to poor performance in physical activity, resulting in the sense of disability in children. These factors contribute to limitations in motor activities [25]. Blind people often have a rare opportunity to become acquainted with their surroundings, limiting their motor experiences. If

Table 2. Means $\pm S D$ tests of ankle and knee range of motion

\begin{tabular}{cccc}
\hline Variables & Limb & Number & Means \pm SD \\
\hline Lunge test & Dominant organ & 32 & $11.06 \pm 1.34$ \\
& Non-dominant organs & $10.33 \pm 0.99$ & $64 \pm 5.86$ \\
Straight leg raise test & Dominant organ & 32 & $60 \pm 5.32$ \\
\hline & Non-dominant organs & & PHYSICAL TREA MENTS
\end{tabular}




\section{Mean of scores obtained by samples}

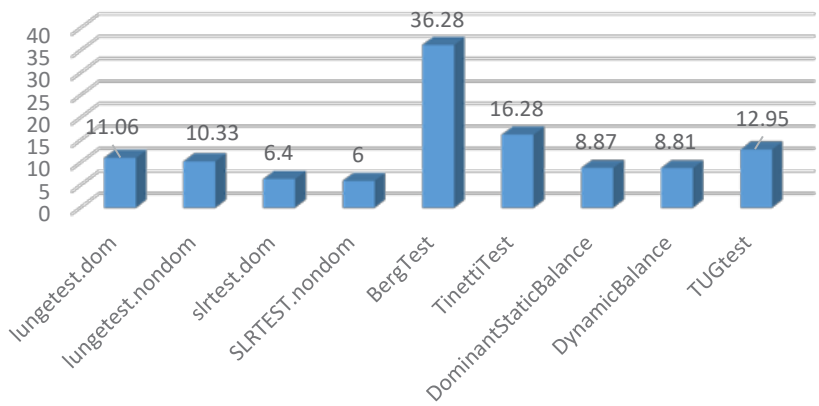

Figure 5. Mean scores obtained by samples

PHYSICAL TREA $\$ MENTS

this lack of opportunity is not compensated, it can lead to secondary physical, mental, and social problems. For example, blindness can cause fear of falling and a sedentary lifestyle leading to several diseases such as obesity, diabetes, high blood pressure, postural abnormalities, and joint mobility limitations [26]. In the present study, similar to other physical fitness factors, the flexibility and mobility limitations are affected by the level of physical activity to contribute to reduced flexibility.

Our results showed significant correlations between the scores obtained from the Lunge test (to assess ankle joint ROM) and static and dynamic balance, the Berg balance scale in both dominant and non-dominant limbs, motor function, and falling risk for the blind people $(\mathrm{P}<0.05)$. Regarding the assessment of the ankle ROM, the results of the present study are consistent with some earlier studies conducted by Basnett et al. [11], Seong- Gil Kim [12], and Martin J. Sepik [10]. Basnett et al. conducted a study on the effect of ankle dorsiflexion ROM on dynamic balance in individuals with CAI, and the results demonstrated significant correlations between dorsiflexion ROM and the anterior reach direction and posterolateral reach direction. Also, impairments in ankle dorsiflexion ROM affect dynamic balance [11].

Several studies have shown significant correlations between the ankle plantar flexion and dorsiflexion ROM, static balance [12], dynamic balance, motor function
[10], walking parameters [7], and risk of falling [27] among both sexes of different age, which are consistent with our results. Muscle weakness is considered a consequence of a sedentary lifestyle, caused by a decrease in muscle size, and is one of the leading causes of falling. In general, fallings and balance and functional impairments are associated with decreased physical activity and the measurement criteria of impaired mobility [27]. Also, there is an association between increased flexibility and improvement in the quality of life and activities of daily living in people. Decreased calf muscle length characterized by a reduction in ankle dorsiflexion with the fully extended knee can occur in males and females during the normal aging process or a sedentary lifestyle.

It has been shown that a decrease in the number and size of slow-twitch and fast-twitch muscle fibers is observed in the disabled and the elderly living a sedentary lifestyle, associated with selective fast fiber atrophy. Muscle fiber atrophy is responsible for a decrease in fiber size and muscle strength of the lower extremities of people living in a sedentary people, which can also be a reason for the reduced muscle length and flexibility observed in the of the lower extremities of people with a sedentary life. Therefore, it can limit the ROM and change a torque around the joints [27-29]. On the other hand, a history of ankle sprains or CAI is observed in blind people due to the high number of falls. Static and dynamic balance impairments are seen in people with a history of ankle

Table 3. Results of Pearson correlation test in Lunge Test with balance

\begin{tabular}{ccccc}
\hline \multirow{2}{*}{ Variables } & Amounts & Static Balance & Dynamic Balance & Balance Scale Berg \\
& The amount of correlation & 0.697 & 0.669 \\
Dominant foot launch test & The significance level & $0.001^{*}$ & $0.001^{*}$ & 0.541 \\
& The amount of correlation & 0.467 & 0.405 & 0.375 \\
\multirow{2}{*}{ Non-dominant foot launch test } & The significance level & $0.007^{*}$ & $0.022^{*}$ & $0.035^{*}$ \\
& & &
\end{tabular}

* Significant level of determinede at $\mathrm{P}<0.05$ 
Table 4. Results of Pearson correlation test in Lunge Test with TUG and Tinetti Test

\begin{tabular}{cccc}
\hline \multicolumn{1}{c}{ Variables } & Amounts & TUG & Tinetti \\
\hline \multirow{2}{*}{ Dominant foot launch test } & The amount of correlation & 0.529 \\
& The significance level & -0.449 & $0.002^{*}$ \\
Non-dominant foot launch test & The amount of correlation & $0.010^{*}$ & 0.395 \\
& The significance level & -0.508 & $0.003^{*}$ \\
\hline
\end{tabular}

* Significant level determinede at $\mathrm{P}<0.05$

Table 5. Results of the Pearson correlation test in SLR test with balance

\begin{tabular}{ccccc}
\hline \multicolumn{1}{c}{ Variables } & Amounts & Static Balance & Dynamic Balance & Balance Scale Berg \\
\hline \multirow{2}{*}{ Dominant foot SLR test } & The amount of correlation & 0.518 & 0.578 & 0.554 \\
& The significance level & $0.002^{*}$ & $0.001^{*}$ & $0.001^{*}$ \\
\multirow{2}{*}{ Non-dominant foot SLR test } & The amount of correlation & 0.496 & 0.538 & 0.492 \\
& The significance level & $0.004^{*}$ & $0.001^{*}$ & $0.004^{*}$ \\
\hline
\end{tabular}

* Significant level of determinede at $\mathrm{P}<0.05$

PHYSICAL TREATMENTS

injury $[30,31]$. The ankle joint ROM is significant because the balance is controlled by the ankle joint and its movements. The proprioception located in the ankle that senses the position of the joints and the stiffness of the non-contractile structures around the joints can also affect static balance control [32].

The results of the present study also indicated significant correlations between scores obtained from the SLR test (to assess ankle joint ROM), static and dynamic balance, the Berg balance scale in both dominant and non-dominant limbs, motor function, and falling risk $(\mathrm{P}<0.05)$. Regarding the balance, the results of this study are inconsistent with the study of Bakhtiari et al. [33] and are consistent with the studies of Chiacchiero et al. [14], Mohammadi et al. [34], Moghadam et al. [35], and Zagyapan et al. [36]. Bakhtiari et al. investigated the relationship between hamstring muscle shortness and dynamic and static balance in young, healthy individuals [33]. The study was conducted on 40 healthy young subjects (20 cases with and 20 cases without the shortness of hamstring as control). The 90-90 test was applied to measure the hamstring length, and the Biodex system was used to evaluate the quality of balance control. They found no relationship between hamstring muscle shortness and the center of pressure fluctuations used as an index of static and dynamic balance [33].
The discrepancy in the results was probably due to the difference in the type of subjects and the balance evaluation test, and the lack of hamstring shortness type. However, they suggested that the hamstring muscle shortening may help maintain balance by increasing joint stiffness, and thus joint stiffness limits abnormalities which can result in increased stability [33]. Chichiro et al. showed a significant association between ROM, flexibility, and balance. Also, the patient's hip, knee, and ankle Range of Motion (ROM) were measured in different directions, and a significant association was found between ROM and balance [14].

Letafatkar et al. examined the effect of six weeks hamstring eccentric exercises on the postural control ability and knee joint proprioception in adolescent football players. Their results showed that hamstring eccentric exercises improved the ROM and had a significant positive effect on the postural control ability and knee joint proprioception in adolescent football players [34]. Moghadam et al. investigated the effect of stretch training on functional dynamic balance performance and ROM in patients with knee osteoarthritis. They found that stretch training can significantly improve functional dynamic balance and ROM in active older men with knee osteoarthritis [35]. Zagyapan et al. also showed that shortness in hamstring group muscles and hip flexors could change in the posture that negatively affected a person's balance [36].

Table 6. Results of the Pearson correlation test in SLR test with TUG and Tinetti Test

\begin{tabular}{cccc}
\hline Variables & Amounts & TUG & Tinetti \\
\hline Dominant foot SLR test & The amount of correlation & -0.504 & 0.589 \\
& The significance level & $0.003^{*}$ & $0001^{*}$ \\
Non-dominant foot SLR test & The amount of correlation & -0.601 & 0.519 \\
* Significant level of P<0.05 & & $0.001^{*}$ & $0.002^{*}$ \\
\hline
\end{tabular}

* Significant level of $\mathrm{P}<0.05$

PHYSICAL TREATMENTS 
On the other hand, studies have shown that reduced ROM in the knees and hips is one of the leading causes of falls, which may be due to the effect of hip stiffness on the dynamic balance of the lower limbs during walking, which can influence the gait pattern [8]. In human movements, there are various strategies such as ankle strategy, hip strategy and gait strategy that play a role in restoring balance. The hamstring is one of the most important muscles involved in hip strategy, and as a postural muscle, together with other posterior muscles, can maintain balance by correcting the displacement of the center of gravity. Therefore, it seems that any disturbance in the function of this muscle can affect balance, motor function, and falling risk. Based on studies conducted on this topic, hamstring shortening is probably one reason that can affect the maintenance of optimal balance and represents a balance impairment.

Given that muscle flexibility has a direct association with balance, resolving the problem of reduced levels of flexibility can be effective in controlling balance. Reduced levels of flexibility can play a significant role in decreasing muscular synergistic adaptations leading to motor control problems. Therefore, long-term training programs such as self-myofascial release, eccentric exercise, or various stretching exercises can increase muscle flexibility leading to improving the position of hip, knee, and ankle joints and increasing muscle contraction and muscular synergistic adaptation. These effects can be considered an effective strategy for improving balance and motor function and the joint ROM. The present study had some limitations. First, we can point to the unisexuality and unavailability of samples. Second, the small sample size may limit the generalization of the obtained data. Third, this study had two parts, the present study is the first part, and the second part includes the use of appropriate exercises to overcome this movement limitation, which because of the coronavirus pandemic, the second part of this study was not conducted. Finally, other variables such as quality of life were not assessed due to time constraints.

\section{Conclusion}

The present study results demonstrated significant correlations between the ankle and knee joint ROM with static and dynamic balance, motor function, and falling risk for blind people. Therefore, it seems necessary to prepare the training programs that effectively increase the hamstring muscle length and use stretching training to increase flexibility and ankle joint ROM for blind people. Teachers and educators of students with visual impairments are advised to constantly monitor the ROM of their students' lower limb joints and, if there is movement limitation, use appropriate exercises to overcome this limitation.

\section{Ethical Considerations}

\section{Compliance with ethical guidelines}

This research wss approved by the Ethics Committee of the Faculty of Physical Education and Sports Sciences, University of Tehran (IR.UT.SPORT.REC.1398.069). The subjects were not forced to continue cooperating. At the same time, the principle of confidentiality was observed regarding all information of individuals.

\section{Funding}

This research did not receive any grant from funding agencies in the public, commercial, or non-profit sectors.

\section{Authors' contributions}

Data collection: Kamal Mohammadkhani and Mohammad Hani Mansori; Data analysis: Mohammad Karimizadeh Ardekani; Conceptualization, Supervision, Methodology, Investigation, Writing - original draft, and Writing - review \& editing: All authors.

\section{Conflict of interest}

The authors declared no conflict of interest.

\section{Acknowledgments}

We thank all the students who participated in the present study, as well as those who helped us with the study.

\section{References}

[1] Ahmadi Barati S, Ahmadi Barati A, Ghaeini S, Ahanjan Sh Halabi F. [The growth status of balance capabilities of low vision children, blind and their healthy counterparts (Persian)]. Journal of Sport Bioscience Researches. 2013; 3(9):69-77. https:// www.sid.ir/en/journal/ViewPaper.aspx?id=340295

[2] Pascolini D, Mariotti SP. Global estimates of visual impairment: 2010. British Journal of Ophthalmology. 2012; 96(5):614-8 [DOI:10.1136/bjophthalmol-2011-300539] [PMID]

[3] Ayvazoglu NR, Oh HK, Kozub FM. Explaining physical activity in children with visual impairments: A family systems approach. Exceptional Children. 2006; 72(2):235-48. [DOI:10. 1177/001440290607200207] 
[4] Häkkinen A, Holopainen E, Kautiainen H, Sillanpää E, Häkkinen K. Neuromuscular function and balance of prepubertal and pubertal blind and sighted boys. Acta Paediatrica. 2006; 95(10):1277-83. [DOI:10.1080/08035250600573144] [PMID]

[5] Blomqvist S, Rehn B. Validity and reliability of the Dynamic One Leg Stance (DOLS) in people with vision loss. Advances in Physiotherapy. 2007; 9(3):129-35. [DOI:10.1080/14038190701395671]

[6] Davarpanah Jazi S, Purrajabi F, Movahedi AR, Jalali S. Effect of selected balance exercises on the dynamic balance of children with visual impairments. Journal of Visual Impairment \& Blindness. 2012; 106(8):466-74. [DOI:10.1177/014548 2X1210600803]

[7] Nodehi Moghadam A, Akhbari B, Bahar Loui H, Jouhari S. [The effect of hip and ankle stretching on elderly balance (Persian)]. Salmand: Iranian Journal of Ageing. 2012; 7(1):41-8. http:// salmandj.uswr.ac.ir/article-1-488-en.html

[8] Kerrigan DC, Lee LW, Collins J, Riley PO, Lipsitz LA. Reduced hip extension during walking: Healthy elderly and fallers versus young adults. Archives of Physical Medicine and Rehabilitation. 2001; 82(1):26-30. [DOI:10.1053/ apmr.2001.18584] [PMID]

[9] McNair PJ, Stanley SN. Effect of passive stretching and jogging on the series elastic muscle stiffness and range of motion of the ankle joint. British Journal of Sports Medicine. 1996; 30(4):313-7. [DOI:10.1136/bjsm.30.4.313] [PMID] [PMCID]

[10] Spink MJ, Fotoohabadi MR, Wee E, Hill KD, Lord SR, Menz HB. Foot and ankle strength, range of motion, posture, and deformity are associated with balance and functional ability in older adults. Archives of Physical Medicine and Rehabilitation. 2011; 92(1):68-75. [DOI:10.1016/j.apmr.2010.09.024] [PMID]

[11] Basnett CR, Hanish MJ, Wheeler TJ, Miriovsky DJ, Danielson EL, Barr J, et al. Ankle dorsiflexion range of motion influences dynamic balance in individuals with chronic ankle instability. International Journal of Sports Physical Therapy. 2013; 8(2):121-8. https://www.ncbi.nlm.nih.gov/pmc/articles/PMC3625791/ [PMID] [PMCID]

[12] Kim SG, Kim WS. Effect of ankle range of motion (ROM) and lower-extremity muscle strength on static balance control ability in Young adults: A regression analysis. Medical Science Monitor. 2018; 24:3168-75. [DOI:10.12659/ MSM.908260] [PMID] [PMCID]

[13] Lim KI, Nam HC, Jung KS. Effects on hamstring muscle extensibility, muscle activity, and balance of different stretching techniques. Journal of Physical Therapy Science. 2014; 26(2):209-13. [DOI:10.1589/jpts.26.209] [PMID] [PMCID]

[14] Chiacchiero M, Dresely B, Silva U, DeLosReyes R, Vorik $B$. The relationship between range of movement, flexibility, and balance in the elderly. Topics in Geriatric Rehabilitation. 2010; 26(2):148-55. [DOI:10.1097/TGR.0b013e3181e854bc]

[15] Hoch MC, Staton GS, McKeon PO. Dorsiflexion range of motion significantly influences dynamic balance. Journal of Science and Medicine in Sport. 2011; 14(1):90-2. [DOI:10.1016/j.jsams.2010.08.001] [PMID]

[16] Lee JW, Yoon SW, Kim JH, Kim YP, Kim Y-N. The effect of ankle range of motion on balance performance of elderly people. Journal of Physical Therapy Science. 2012; 24(10):991-4. [DOI:10.1589/jpts.24.991]
[17] Custer L, Cosby N. Reliability of three inclinometer placements for weight-bearing dorsiflexion. Athletic Training and Sports Health Care. 2018;10(4):181-7. [DOI:10.3928/1942586420180312-01]

[18] Miyamoto N, Hirata K, Kimura N, Miyamoto-Mikami E. Contributions of hamstring stiffness to straight-leg-raise and sit-and-reach test scores. International Journal of Sports Medicine. 2018; 39(02):110-4. [DOI:10.1055/s-0043-117411] [PMID]

[19] Salar S, Daneshmandi H. [Relationship between lumbarpelvic function and static and dynamic balance in children with autism spectrum disorders (Persian)]. Scientific Journal of Rehabilitation Medicine. 2017; 6(2):168-79. [DOI:10.22037/ jrm.2017.1100311]

[20] Raji P. Functional balance tests. Auditory and Vestibular Research. 2012; 21(4):1-9. https:/ /avr.tums.ac.ir/index.php/ avr/issue/view/43

[21] Sadeghi H, Norouzi H, Karimi Asl A, Montazer MR. [Functional training program effect on static and dynamic balance in male able-bodied elderly (Persian)]. Salmand: Iranian Journal of Ageing. 2008; 3(2):565-71. http:// salmandj.uswr. ac.ir/article-1-91-en.html

[22] Sadeghi S, Mahdavinezhad R, Kamali A. [Effectiveness of core stabilization exercises on balance and gait speed of blind students (Persian)]. Journal of Research in Exercise Rehabilitation. 2016; 4(7):21-30. [DOI:10.22084/RSR.2016.1590]

[23] Wood-Dauphinee S, Berg K, Bravo G, Williams J. The Balance Scale: Responsiveness to clinically meaningful changes. Canadian Journal of Rehabilitation. 1996; 10:35-50. https:/ / scholar.google.com/scholar?cluster $=3460013456585313718$ $\& h l=e n \& a s \_s d t=2005 \&$ sciodt $=0,5$

[24] Houwen S, Visscher C, Lemmink K, Hartman E. Motor skill performance of school-age children with visual impairments. Developmental Medicine \& Child Neurology. 2008; 50(2):139-45. [DOI:10.1111/j.1469-8749.2007.02016.x] [PMID]

[25] Houwen S, Hartman E, Visscher C. Physical activity and motor skills in children with and without visual impairments. Medicine \& Science in Sports \& Exercise. 2009; 41(1):103-9. [DOI:10.1249/MSS.0b013e318183389d] [PMID]

[26] Kozub FM. Motivation and physical activity in adolescents with visual impairments. RE: View. 2006; 37(4):149-60. https://search.proquest.com/openview/ad5a4688a26f1dbb70 1573bf763e6c31/1?pq-origsite $=$ gscholar\&cbl $=48930$

[27] Rodacki AL, Souza RM, Ugrinowitsch C, Cristopoliski F, Fowler NE. Transient effects of stretching exercises on gait parameters of elderly women. Manual Therapy. 2009; 14(2):167-72. [DOI:10.1016/j.math.2008.01.006] [PMID]

[28] Gajdosik RL, Vander Linden DW, McNair PJ, Williams AK, Riggin TJ. Effects of an eight-week stretching program on the passive-elastic properties and function of the calf muscles of older women. Clinical Biomechanics. 2005; 20(9):97383. [DOI:10.1016/j.clinbiomech.2005.05.011] [PMID]

[29] Gajdosik RL, Vander Linden DW, McNair PJ, Riggin TJ, Albertson JS, Mattick DJ, et al. Slow passive stretch and release characteristics of the calf muscles of older women with limited dorsiflexion range of motion. Clinical Biomechanics. 2004; 19(4):398-406. [DOI:10.1016/j.clinbiomech.2003.12.009] [PMID]

[30] Wikstrom EA, Fournier KA, McKeon PO. Postural control differs between those with and without chronic ankle insta- 
bility. Gait \& Posture. 2010; 32(1):82-6. [DOI:10.1016/j.gaitpost.2010.03.015] [PMID]

[31] Arnold BL, De La Motte S, Linens S, Ross SE. Ankle instability is associated with balance impairments: A meta-analysis. Medicine \& Science in Sports \& Exercise. 2009; 41(5):1048-62. [DOI:10.1249/MSS.0b013e318192d044] [PMID]

[32] Wang HK, Chen CH, Shiang TY, Jan M-H, Lin KH. Riskfactor analysis of high school basketball-player ankle injuries: A prospective controlled cohort study evaluating postural sway, ankle strength, and flexibility. Archives of Physical Medicine and Rehabilitation. 2006; 87(6):821-5. [DOI:10.1016/j.apmr.2006.02.024] [PMID]

[33] Bakhtiary AH, Fatemy E, Hedayati R, Ghorbani R, Gillani $\mathrm{M}$. [The relationship between hamstring muscle shortness and dynamic and static balances in young healthy individuals (Persian)]. Koomesh. 2015; 16(4):536-43. http:/ / koomeshjournal.semums.ac.ir/article-1-2635-en.html

[34] Mohammadi A, Letafatkar A, Hosseini SH, Heshmati S. [The effect of six weeks hamstring eccentric exercises on the postural control ability and knee joint proprioception in adolescent football players (Persian)]. Journal of Sport Biomechanics. 2017; 3(3):15-25. http://biomechanics.iauh.ac.ir/ article-1-136-en.html

[35] Baverdi Moghaddam E, Shujauddin SS. [The effect of a stretching training on functional dynamic balance preformance and range of motion patients with knee osteoarthritis (Persian)]. Journal of Sport Biomechanics. 2017; 2(4):5-18. http://biomechanics.iauh.ac.ir/article-1-102-en.html

[36] Zagyapan R, Iyem C, Kurkcuoglu A, Pelin C, Agah Tekindal $M$. The relationship between balance, muscles, and anthropomorphic features in young adults. Anatomy Research International. 2012; 146063. [DOI:10.1155/2012/146063] [PMID] [PMCID] 